\title{
Role of Lysines in Cytochrome c-Cardiolipin Interaction
}

\author{
Federica Sinibaldi, ${ }^{\dagger}$ Barry D. Howes, ${ }^{\ddagger}$ Enrica Droghetti, ${ }^{\dagger}$ Fabio Polticelli, ${ }^{\S}, \|$ Maria Cristina Piro, ${ }^{\perp}$ \\ Donato Di Pierro, ${ }^{\dagger}$ Laura Fiorucci, ${ }^{\dagger}$ Massimo Coletta, ${ }^{\dagger}$ Giulietta Smulevich, ${ }^{\ddagger}$ and Roberto Santucci ${ }^{*}{ }^{\dagger}$ \\ ${ }^{\dagger}$ Department of Clinical Sciences and Translational Medicine, University of Rome 'Tor Vergata', 00133 Rome, Italy \\ ${ }^{\ddagger}$ Department of Chemistry "Ugo Schiff”, University of Florence, 50019 Sesto Fiorentino, Italy \\ ${ }^{\S}$ Department of Sciences, University Roma Tre, 00146 Rome, Italy \\ "National Institute of Nuclear Physics, 'Roma Tre' Section, 00146 Rome, Italy \\ ${ }^{\perp}$ Department of Experimental Medicine and Surgery, University of Rome 'Tor Vergata', 00133 Rome, Italy
}

Supporting Information

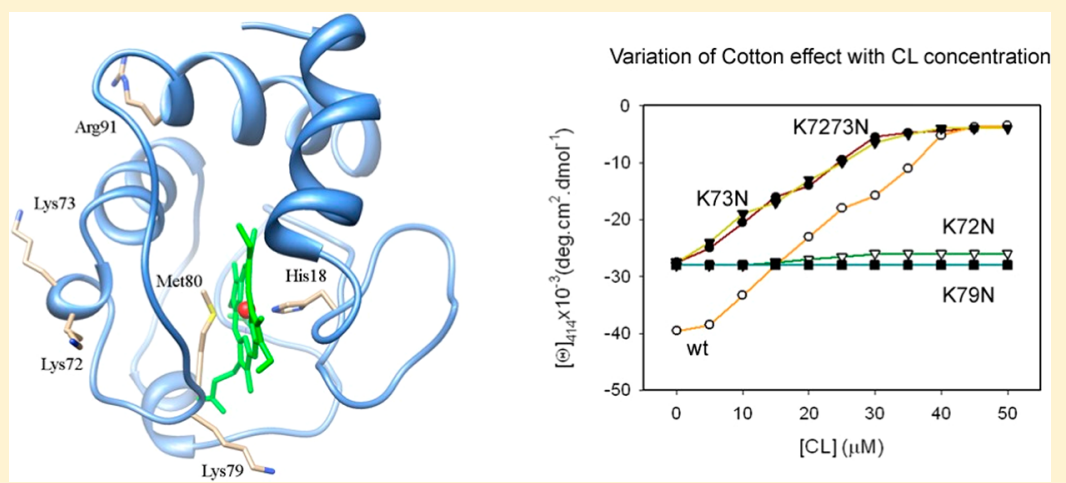

ABSTRACT: Cytochrome $c$ undergoes structural variations during the apoptotic process; such changes have been related to modifications occurring in the protein when it forms a complex with cardiolipin, one of the phospholipids constituting the mitochondrial membrane. Although several studies have been performed to identify the site(s) of the protein involved in the cytochrome $c$-cardiolipin interaction, to date the location of this hosting region(s) remains unidentified and is a matter of debate. To gain deeper insight into the reaction mechanism, we investigate the role that the Lys72, Lys73, and Lys79 residues play in the cytochrome $c$-cardiolipin interaction, as these side chains appear to be critical for cytochrome $c$-cardiolipin recognition. The Lys72Asn, Lys73Asn, Lys79Asn, Lys72/73Asn, and Lys72/73/79Asn mutants of horse heart cytochrome $c$ were produced and characterized by circular dichroism, ultraviolet-visible, and resonance Raman spectroscopies, and the effects of the mutations on the interaction of the variants with cardiolipin have been investigated. The mutants are characterized by a subpopulation with non-native axial coordination and are less stable than the wild-type protein. Furthermore, the mutants lacking Lys72 and/or Lys79 do not bind cardiolipin, and those lacking Lys73, although they form a complex with the phospholipid, do not show any peroxidase activity. These observations indicate that the Lys72, Lys73, and Lys79 residues stabilize the native axial Met80-Fe(III) coordination as well as the tertiary structure of cytochrome $c$. Moreover, while Lys 72 and Lys79 are critical for cytochrome $c$-cardiolipin recognition, the simultaneous presence of Lys72, Lys73, and Lys79 is necessary for the peroxidase activity of cardiolipin-bound cytochrome $c$.

\footnotetext{
Cytochrome $c($ cyt $c)$ is a single-chain hemoprotein of 104 amino acids containing three major and two minor $\alpha$ helices in the structure, with the prosthetic group lying within a crevice lined with hydrophobic residues. The heme is covalently attached to the polypeptide chain by two thioether bridges with residues Cys 14 and Cys17, while His 18 and Met 80 are the axial ligands of the six-coordinated low-spin heme iron in the native state. As a mitochondrial peripheral membrane protein, cyt $c$ acts between the inner and outer membrane, mediating electron transfer between different proteins of the respiratory chain (i.e., between cyt $c$ reductase and cyt $c$ oxidase).

The observation that cyt $c$ plays a role in cell apoptosis after its release from the mitochondrion has renewed interest in this
}

protein in recent years. ${ }^{1-3}$ Approximately $15 \%$ of the protein is tightly bound to cardiolipin (CL), one of the phospholipids constituting the mitochondrial membrane. ${ }^{4-10}$ The remaining protein is free or interacts very weakly with the membrane via electrostatic interactions and can be readily mobilized. Whereas the free (or loosely bound) cyt $c$ participates in electron transfer, inhibits ROS formation, and prevents oxidative stress, the tightly bound protein can acquire peroxidase activity, an event crucial for initiating the apoptotic process. ${ }^{4}$ During

Received: March 13, 2013

Revised: $\quad$ May 27, 2013

Published: June 5, 2013 

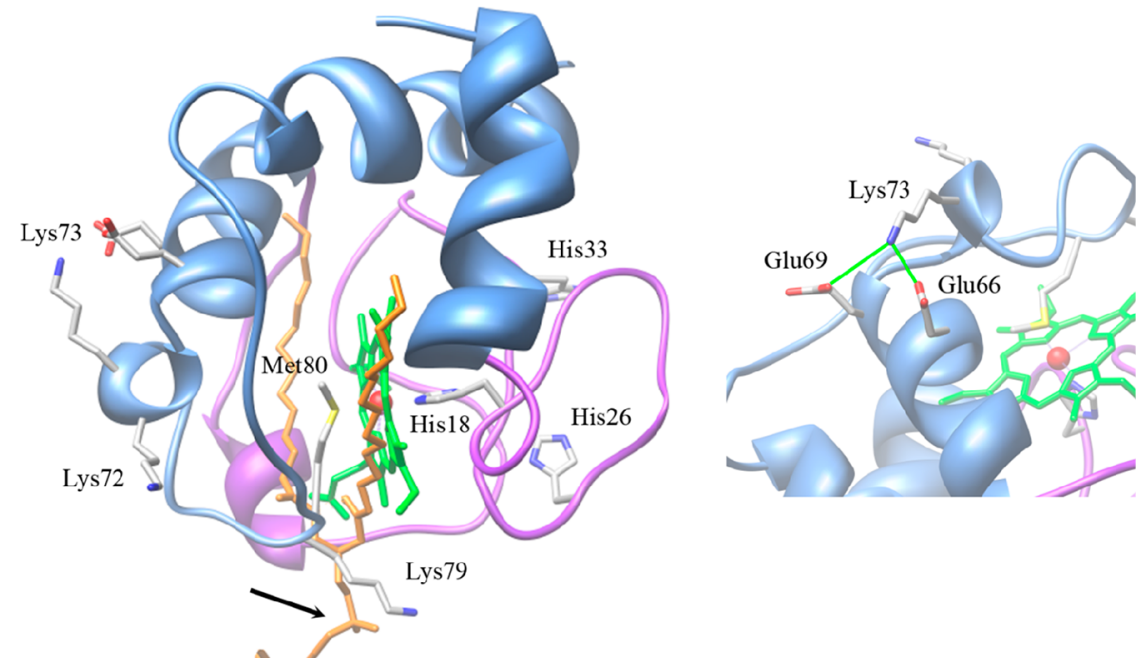

Figure 1. Schematic representation (left) of the three-dimensional structure of horse heart cyt $c$. The heme group, with Fe(III) bound to His 18 and Met80, is colored green. The region of residues $15-60$ is colored purple to underline its poor secondary structure content. CL is colored orange with two acyl chains inserted in the protein structure according to the interaction model proposed by Sinibaldi et al. ${ }^{8}$ Note the opposite orientation of Lys73 as compared to that of Lys72 and Lys79, and the proximity of the Lys79 amino group to one of the CL phosphate groups (indicated by the black arrow). Detail of the salt bridges (right) anchoring Lys73 to Glu66 and Glu69. This figure has been generated using the horse heart cyt $c$ threedimensional structure deposited in the Protein Data Bank as entry $1 \mathrm{AKK}^{46}$ with UCSF Chimera. ${ }^{47}$

apoptosis, cyt $c$ is released from the mitochondrial interface space into the cytosol, an event that implies dissociation of the protein from the mitochondrial membrane. ${ }^{11,12}$ The interaction of cyt $c$ with CL plays a key role in the cell because the interaction modulates protein function, determining whether cyt $c$ conducts its "normal" role in the respiratory chain or is released into the cytosol where it participates in the apoptotic event.

The structural changes observed in cyt $c$ upon apoptosis have been related to modifications occurring when the protein forms a complex with $\mathrm{CL},{ }^{5-8}$ with formation of a heterogeneous ensemble of non-native protein species. ${ }^{13}$ The CL-bound cyt $c$ shows an altered tertiary structure and a perturbed heme crevice; furthermore, the native Met80-Fe(III) axial bond is lost. Depending on the conditions, the sixth coordination position of the heme iron remains unbound or is occupied by another side chain (possibly a lysine). ${ }^{6,14,15}$ The partially unfolded conformation of phospholipid membrane-bound cyt $c$ favors the peroxidase activity of the protein, allowing the access of small molecules (such as $\mathrm{H}_{2} \mathrm{O}_{2}$ ) into the heme pocket of the macromolecule. $^{16}$

As a powerful CL-specific peroxidase, the cyt $c-C L$ complex generates CL hydroperoxides, which actively participate in the release of cyt $c$ (and of other pro-apoptotic factors) from the mitochondrial membrane. ${ }^{17,18}$ Thus, while the native fold is important for cyt $c$ to function as an electron carrier, the nonnative compact conformation of the CL-bound protein favors its peroxidase activity, an event important for the execution of the apoptotic program.

In the past two decades, the mechanism of cyt c-CL complex formation has been widely investigated. The first studies of Kinnunen and collaborators revealed that cyt $c$ binds to $\mathrm{CL}$ through two binding sites, which were called the A-site and the $\mathrm{C}$-site. ${ }^{19}$ At the A-site, the interaction is electrostatic in nature and involves positively charged residues of cyt $c$ (namely, Lys72 and Lys73) and the deprotonated negatively charged phosphate group of CL. Conversely, at the C-site, the protein$\mathrm{CL}$ interaction is hydrophobic and is likely stabilized by the $\mathrm{H}$ - bond formed by Asn52 with the protonated (uncharged) phosphate group of CL. Ionic strength influences and modulates the cyt $c-C L$ interaction around neutrality, because the cyt $c-C L$ complex spontaneously forms at low ionic strengths but promptly dissociates as the ionic strength is increased. 5,6 The "extended lipid conformation" model, formulated by Kinnunen and collaborators, ${ }^{19,20}$ hypothesizes that at the C-site one acyl chain of CL is accommodated in the protein interior by extending from the surface to the heme pocket region through a hydrophobic channel close to the small helix comprising the invariant residue Asn52. According to this model, the other chain of the phospholipid points in the opposite direction from the headgroup. The hypothesis that upon complex formation the heme pocket region of cyt $c$ is markedly altered ${ }^{5}$ found support from the studies of Stewart et al., who demonstrated that the interaction of cyt $c$ with fatty acids induces the cleavage of the native $\mathrm{Fe}-\mathrm{Met} 80$ axial bond. ${ }^{21}$

Despite several studies performed to identify the site(s) of the protein involved in the cyt $c-C L$ interaction, to date the location of these hosting region(s) remains unidentified and is matter of debate. A recent study locates this site in the region containing a network of positively charged residues located in the heme-binding region (Lys72, Lys73, and Lys86). It is proposed that the cleft formed by these side chains permits penetration of the acyl chain deep into the protein until it reaches the heme pocket region. ${ }^{7}$ This model represents a plausible alternative to the extended lipid conformation model described above. ${ }^{19}$

Very recently, the hypothesis that two acyl chains of CL, instead of one, may penetrate inside the protein during complex formation has been formulated. ${ }^{8}$ This model is based on two main considerations: (i) the evidence that the cyt $c-C L$ binding reaction is characterized by two distinct transitions ${ }^{6}$ and (ii) the observation that $\mathrm{CL}$, which possesses a unique structure with respect to all the other phospholipids forming the mitochondrial membrane,$^{22,23}$ is the only phospholipid able to bind cyt $c$ tightly. According to this model, upon complex 
formation, the CL binding to cyt $c$ involves electrostatic interactions of CL phosphate groups with Lys79 and Lys72.

To gain deeper insight into this disputed point, we have investigated the role that residues Lys72, Lys73, and Lys79 (see Figure 1) play in the cyt $c-C L$ interaction, because these side chains appear to be deeply involved in cyt $c-C L$ recognition. ${ }^{7}$ To this end, the Lys72Asn, Lys73Asn, Lys79Asn, Lys72/73Asn, and Lys72/73/79Asn mutants of horse heart cyt $c$ were produced and characterized. Through the Lys $\rightarrow$ Asn mutation, positively charged residues are replaced with polar side chains carrying no net charge, under the conditions investigated. Equine cyt $c$ is the protein utilized for this study because it behaves very much like its human counterpart ${ }^{24}$ and, unlike yeast cyt $c$, actively participates in cell apoptosis. ${ }^{4,15,25-28}$

In contrast with other reports, this investigation has been conducted on the ferric form of the protein. In the cytoplasm, ferric (not ferrous) cyt $c$ binds APAf- 1 to form the complex that initiates the execution of the apoptotic process through the activation of pro-caspase $9 .^{29}$

\section{EXPERIMENTAL PROCEDURES}

Construction of the Horse cyt $c$ Expression System. A version of the horse cyt $c$ synthetic gene was designed on the basis of the sequence of a previously reported cyt $c$ synthetic gene $^{25,29}$ and its synthesis accomplished by Primm srl (Milan, Italy). The synthetic gene was flanked by the NcoI and BamHI restriction sites, at the $5^{\prime}$ and $3^{\prime}$ ends, respectively. The pBTRI plasmid was converted to the horse cyt $c$ expression plasmid by removing the yeast iso-1-cyt $c$ gene and replacing it with the new synthetic horse cyt $c$ gene, by using the unique $\mathrm{NcoI}$ and BamHI sites. The sequence of the expression construct (pHCyc) was confirmed by DNA sequence analysis (MMedical, Milan, Italy). Plasmid pHCyc was then subjected to one round of mutagenesis, which introduced the Lys72Asn, Lys73Asn, and Lys79Asn substitutions into the horse cyt $c$ gene.

Cell Growth and Purification of Recombinant Proteins. The expression plasmids of horse cyt $c$ were introduced into Escherichia coli JM 109 as the wild type (wt) or its variants. Protein expression and purification of the recombinant protein were then conducted as previously described. ${ }^{30}$ Briefly, bacteria containing the pBTRI (or the mutated) plasmid were grown at $37^{\circ} \mathrm{C}$, in $2 \mathrm{~L}$ of SB medium containing $100 \mu \mathrm{g} / \mathrm{mL}$ ampicillin to an absorbance of $0.3 \mathrm{OD}$ at $600 \mathrm{~nm}$. Induction was accomplished by adding IPTG (isopropyl $\beta$-D-thiogalactopyranoside) to a final concentration of $0.75 \mathrm{mM}$. Cells were then incubated at $37{ }^{\circ} \mathrm{C}$ overnight, harvested by centrifugation, and frozen at $-80^{\circ} \mathrm{C}$. After the cells had thawed, the reddish pellets were resuspended in $50 \mathrm{mM}$ Tris- $\mathrm{HCl}$ buffer $(\mathrm{pH} 8.0)(3-4$ $\mathrm{mL} / \mathrm{g}$ of wet cells $)$. Lysozyme $(1 \mathrm{mg} / \mathrm{mL})$ and DNase $(5 \mu \mathrm{g} /$ $\mathrm{mL}$ ) were then added to the homogenized cells. The suspension was left in ice for $1 \mathrm{~h}$ and then sonicated for 1 min, at medium intensity. After centrifugation, the supernatant was dialyzed overnight against $10 \mathrm{mM}$ phosphate buffer $(\mathrm{pH}$ 6.2) and loaded on a CM 52 column ( $40 \mathrm{~mL}$ bed volume) equilibrated with the same buffer. Purification was performed by eluting the protein with 1 volume of $45 \mathrm{mM}$ phosphate $(\mathrm{pH}$ 6.8) and $250 \mathrm{mM} \mathrm{NaCl}$, following a previously published procedure. $^{31}$ After purification, the recombinant proteins $(\sim 500 \mu \mathrm{M})$ had a purity of $>98 \%$ [determined by sodium dodecyl sulfate-polyacrylamide gel electrophoresis analysis and reverse phase high-performance liquid chromatography (not shown)] and stored at $-80{ }^{\circ} \mathrm{C}$ in $200 \mu \mathrm{L}$ aliquots. The same procedure was used for the purification of the Lys72/73Asn/ His26Tyr and Lys72/73Asn/His33Tyr mutants.

Circular Dichroism (CD) Measurements. CD measurements were taken at $25^{\circ} \mathrm{C}$ using a Jasco (Tokyo, Japan) J-710 spectropolarimeter equipped with a personal computer as a data processor. In the near-UV $(270-320 \mathrm{~nm})$ and Soret $(380-450 \mathrm{~nm})$ regions, the molar ellipticity, $[\Theta]$ (degrees square centimeters per decimole), is expressed on a molar heme basis. Binding of cyt $c$ (as wt or Lys $\rightarrow$ Asn variants) to $\mathrm{CL}$ liposomes was investigated by following the changes induced in the Soret CD spectrum $(400-450 \mathrm{~nm})$ of the protein by stepwise addition of few microliters of a $2.5 \mathrm{mM} \mathrm{CL}$ buffered solution to a $10 \mu \mathrm{M}$ cyt $c$ buffered solution. The buffer consisted of $25 \mathrm{mM}$ Hepes and $0.1 \mathrm{mM}$ EDTA ( $\mathrm{pH} \mathrm{7.0)}$. Dichroic spectra were recorded after samples had been mixed for $10(\mathrm{wt})$ or $20 \mathrm{~min}$ (variants).

Electronic Absorption Measurements. Electronic absorption measurements were taken at $25{ }^{\circ} \mathrm{C}$ using a Jasco V530 or double-beam Cary 5 spectrophotometer (Varian, Palo Alto, CA). The cyt $c$ concentration was determined on the basis of an extinction coefficient $(\varepsilon)$ of $106 \mathrm{mM}^{-1} \mathrm{~cm}^{-1}$ at $408 \mathrm{~nm}$.

Resonance Raman Measurements. The resonance Raman (RR) spectra were recorded using a $5 \mathrm{~mm}$ NMR tube and by excitation with the $406.7 \mathrm{~nm}$ line of a $\mathrm{Kr}^{+}$laser (Innova 300 C, Coherent, Santa Clara, CA). Backscattered light from a slowly rotating NMR tube was collected and focused into a triple spectrometer (consisting of two Acton Research SpectraPro 2300i instruments and a SpectraPro 2500i instrument in the final stage with a grating of 3600 grooves $/ \mathrm{mm}$ ) working in the subtractive mode, equipped with a liquid nitrogen-cooled CCD detector. A spectral resolution of $1 \mathrm{~cm}^{-1}$ was calculated theoretically on the basis of the optical properties of the spectrometer. However, for the moderately broad experimental RR bands observed in this study $(\sim 10$ $\mathrm{cm}^{-1}$ ), the effective spectral resolution will in general be lower. The $\mathrm{RR}$ spectra were calibrated with indene and $\mathrm{CCl}_{4}$ as standards to an accuracy of $1 \mathrm{~cm}^{-1}$ for intense isolated bands. The spectral changes induced by CL liposomes were monitored following the stepwise addition of $0.8 \mu \mathrm{L}$ aliquots of CL (2.5 $\mathrm{mM})$ buffered solution to $50 \mu \mathrm{L}$ of a $30 \mu \mathrm{M}$ protein buffered solution, recording the spectrum $20 \mathrm{~min}$ after mixing. The CL:protein molar ratios reported in the figure captions correspond to the CL concentration above which no further spectral variations were observed. It is also noted that the frequencies of the RR bands observed at 412 and $418 \mathrm{~cm}^{-1}$, assigned to the $\delta(\mathrm{CCC})_{2,4}$ bending vibrations of the thioether bridges, ${ }^{32}$ have been determined by a curve-fitting program (Lab Calc, Galactic) to simulate the spectra (Figure S1 of the Supporting Information). A Lorentzian line shape with a line width of $9 \mathrm{~cm}^{-1}$ was used. Any variation in the overall line shape of these two bands can be ascribed to changes in their relative intensities. It is noted that in the case of the Lys72/ 73Asn/His33Tyr and Lys72/73/79Asn triple mutants the band at $412 \mathrm{~cm}^{-1}$ shifts to $413 \mathrm{~cm}^{-1}$.

Peroxidase Activity Assay. The peroxidase activities of free wt cyt $c$ and its mutants, the cyt $c-C L$ complex, and the mutants in the presence of $\mathrm{CL}$ were determined by measuring the $\mathrm{H}_{2} \mathrm{O}_{2}$-dependent oxidation of guaiacol as a function of guaiacol concentration. The steady-state kinetics of guaiacol oxidation to give its tetramer was measured spectrophotometrically at $470 \mathrm{~nm}$ and $25{ }^{\circ} \mathrm{C}\left(\varepsilon_{470}=26.6 \mathrm{mM}^{-1} \mathrm{~cm}^{-1}\right)$. 


\section{RESULTS}

Lys72, Lys73, and Lys79 are located in the Met80-containing loop adjacent to the heme pocket region (Figure 1, left panel). As invariant (Lys72 and Lys79) or largely invariant (Lys73) residues, the three lysines are expected to play a central role in the stabilization and the correct functionality of the native protein. When one (or more) of these lysines is (are) replaced, the loop segment partially unfolds and the heme pocket region is altered; in particular, the strength of the Met80-Fe(III) axial bond is significantly decreased. ${ }^{7}$ Because the segment of 70-80 residues is a largely invariant region in c-class cytochromes and is involved (as recently reported) in the cyt $c-C L$ binding process, ${ }^{7,8}$ in this paper the properties of the Lys72Asn, Lys73Asn, Lys79Asn, Lys72/73Asn, and Lys72/73/79Asn mutants of equine cyt $c$ were characterized by $\mathrm{CD}, \mathrm{UV}-\mathrm{vis}$, and resonance Raman spectroscopies to assess the involvement of the lysine residues in the binding reaction with CL.

Stability of the Mutants. The stability of the mutants was investigated by following the $\mathrm{Gdm}-\mathrm{HCl}$-induced protein unfolding process. The denaturation profiles are shown in Figure 2. The experimental points refer to the ellipticity

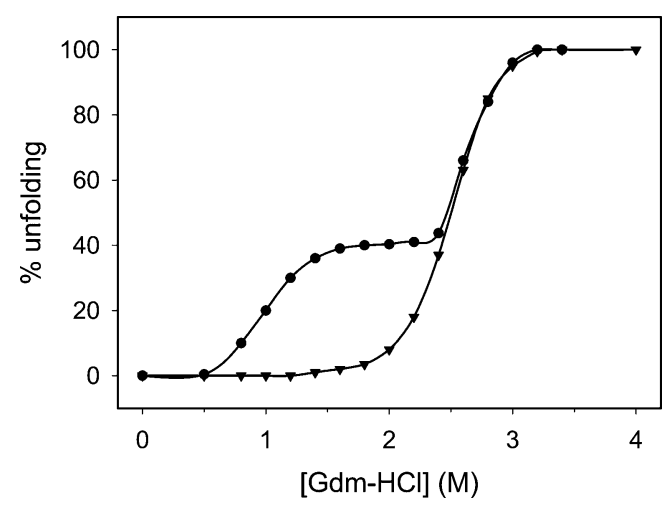

Figure 2. Unfolding profiles of the Lys72Asn, Lys73Asn, Lys79Asn, and Lys72/73Asn mutants $(\bullet)$ and native cyt $c(\boldsymbol{\nabla})$ in the presence of increasing amounts of $\mathrm{Gdm}-\mathrm{HCl}$. The mutants show extremely similar profiles. Dichroic measurements were taken at $222 \mathrm{~nm}$. The protein concentration was $10 \mu \mathrm{M}$ in $20 \mathrm{mM}$ Hepes and $0.1 \mathrm{mM}$ EDTA ( $\mathrm{pH}$ 7.0). The temperature was $25^{\circ} \mathrm{C}$.

measured at $222 \mathrm{~nm}$, a probe for the $\alpha$-helix structure; changes in ellipticity are expressed as a percentage of unfolding. Unlike the native protein, the mutants display biphasic unfolding profiles in which the first transition is characterized by a midtransition denaturant concentration $\left(c_{1 / 2}=1.0 \mathrm{M}\right)$ and the second transition by a $c_{1 / 2}$ value of $2.5 \mathrm{M}$. These results suggest that some of the helix segments present in the native protein unfold during the first transition. The two longest helices, namely, the $\mathrm{N}$ - and $\mathrm{C}$-terminal helices, are known to be very stable; ${ }^{33}$ therefore, the segments expected to unfold are the helix of residues 50-54, the 60s' helix (residues 61-68), and the very short helix of residues 72-74. Considering that the latter two helices are held together by a salt bridge involving Lys73 and Glu66, the conformational changes involving the helix of residues $72-74$ are expected to destabilize the $60 \mathrm{~s}^{\prime}$ helix as well.

Structural Properties of the Mutants As Revealed by CD. The mutants show well-defined far-UV dichroic spectra (not shown) typical of proteins with $\alpha$-helix secondary structure, and ellipticity comparable to that of the native form. Panels A and B of Figure 3 illustrate the Soret (400-450 $\mathrm{nm}$, related to the heme pocket structure) and near-UV (270-
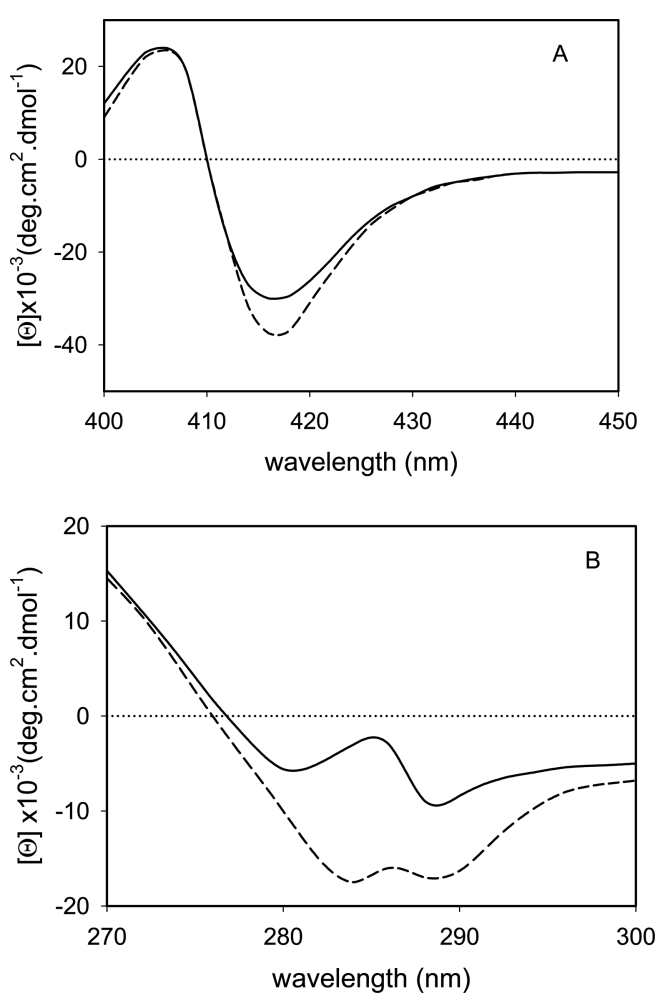

Figure 3. Soret CD (A) and near-UV (B) spectra of the Lys72Asn, Lys73Asn, Lys79Asn, Lys72/73Asn, and Lys72/73/79Asn mutant $(-)$. The mutants show extremely similar spectra in both regions investigated. The CD spectrum of the native protein $(\cdots)$ is reported for comparative purposes. Other experimental conditions as for Figure 2.

$300 \mathrm{~nm}$, related to the Trp59-surrounding microenvironment) CD spectra, respectively. The Soret CD spectra of the mutants are very similar; with respect to the wild-type (wt) protein, the $416 \mathrm{~nm}$ Cotton effect is slightly shifted $(\sim 2 \mathrm{~nm})$ toward the blue and is approximately $30 \%$ weaker. Because this signal is attributed to the Phe82- and Met80-heme interaction and is considered a probe for the environment on the Met80 side of the heme pocket, ${ }^{34,35}$ a weaker $416 \mathrm{~nm}$ Cotton effect is associated with an increased distance between residues Phe 82 and Met80 and the heme group, possibly related to the conformational change of the loop of residues 70-85 induced by mutation(s). According to previous studies, only the Met80-Fe-His coordinated protein contributes to the 416 nm dichroic signal; ${ }^{30,35}$ therefore, a weakened Cotton effect reveals formation of a minor $(\sim 30 \%)$ heterogeneous subpopulation of species having non-native $\mathrm{X}-\mathrm{Fe}-\mathrm{His} 18$ axial coordination (where $\mathrm{X}$ is a misligated endogeneous ligand) in equilibrium with the major Met80-Fe-His 18 coordinated species. Moreover, the near-UV CD spectrum of the mutants (Figure 3B), associated with the Trp59-heme propionate $\mathrm{H}$-bonding, suggests that the distance between the two interacting groups is increased, as indicated by the weaker dichroic bands centered at 284 and $289 \mathrm{~nm}$.

Mutants Binding to CL Liposomes Followed by CD. Figure 4 shows the titration curve of the Lys72/73Asn (O), Lys73Asn ( $\mathbf{\nabla})$, Lys72Asn ( $\nabla$ ), and Lys79Asn ( $\mathbf{\square}$ ) mutants binding to large $(100 \mu \mathrm{m})$ unilamellar CL liposomes. The 


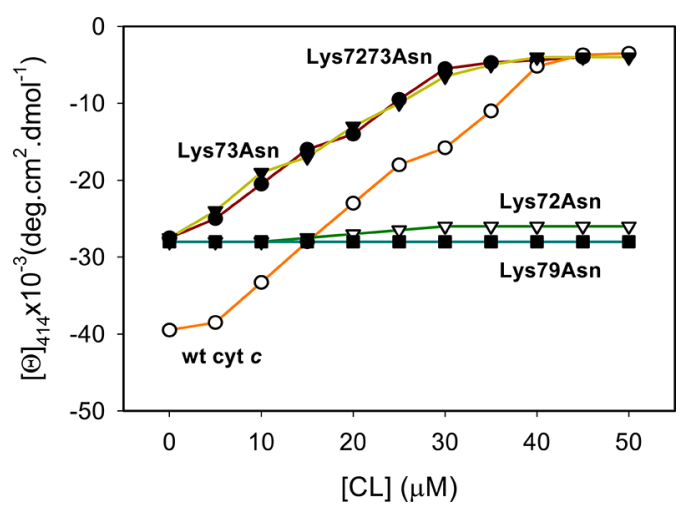

Figure 4. Titration curve of CL vesicles binding to the Lys72/73Asn $(\mathbf{\bullet})$, Lys73Asn $(\boldsymbol{\nabla})$, Lys72Asn $(\nabla)$, and Lys79Asn $(\boldsymbol{\square})$ mutants. Experimental points refer to the variation of the $414 \mathrm{~nm}(416 \mathrm{~nm}$ for the native protein) Cotton effect induced by stepwise addition of CL to a $10 \mu \mathrm{M}$ protein solution. The titration curve of native equine cyt $c$ (O) is reported for comparative purposes. Experimental points are the average of at least three measurements. Other conditions are as for Figure 2 .

experimental points refer to the variation of the $414 \mathrm{~nm}$ [ 416 $\mathrm{nm}$ for the wt protein $(\mathrm{O})]$ Cotton effect induced by stepwise addition of $\mathrm{CL}$ vesicles to a $10 \mu \mathrm{M}$ protein solution. The marked decrease in the $414 \mathrm{~nm}$ Cotton effect observed after addition of $\mathrm{CL}$ to the Lys72/73Asn and Lys73Asn solution indicates that binding of cyt $c$ to the $\mathrm{CL}$ vesicles (CL concentration higher than its critical micelle concentration) alters the heme pocket region in a manner similar to that observed for native cyt $c$, hence, in agreement with the progressive growth of a species with non-native heme coordination upon increasing CL concentration. Furthermore, the mutants show a higher affinity for the phospholipid. The $416 \mathrm{~nm}$ Cotton effect of the native protein fully disappears upon complex formation (6:1 CL:cyt $c$ molar ratio in solution), thus suggesting that the CL-bound protein has non-native heme coordination. ${ }^{6,35}$ The same can be expected for the Lys72/73Asn and Lys73Asn mutants. The behavior of the other mutants is markedly different; the Lys72Asn variant shows very little change in the $414 \mathrm{~nm}$ dichroic band, and the Lys79Asn variant does not seem to react with CL. A similar result was obtained for the Lys72/73/79Asn triple mutant (data not shown). With respect to wt cyt $c$, whose reaction with $\mathrm{CL}$ vesicles requires approximately $1-2 \mathrm{~min}$ to form the complex ${ }^{6}$ the mutants require a longer reaction time of approximately $10-12 \mathrm{~min}$. This may derive from the unfolding of the loop of residues $75-87$ in the mutants, which alters the conformation of the region hindering the insertion of the acyl chain of CL. As illustrated in Figure 4, while the Lys72/73Asn and Lys73Asn mutants form the protein-CL complex through two distinct transitions (like the native protein), the Lys72Asn and Lys79Asn (as well as the Lys72/73/79Asn) mutants do not bind the phospholipid. Furthermore, like wt cyt $c$, the Lys73Asn and Lys72/73Asn mutants do not react with CL at high ionic strengths (data not shown). ${ }^{6}$

UV-Vis and RR Spectra of the Mutants. The UV-vis and RR spectra confirm that the single Lys79Asn and triple Lys72/73/79Asn mutations have an only minor effect on the wt protein and that their interaction with $\mathrm{CL}$ is relatively limited (see Figures S2 and S3 of the Supporting Information). Figures 5-7 show a comparison of the electronic absorption and RR spectra of the wt protein and the Lys72Asn, Lys73Asn,
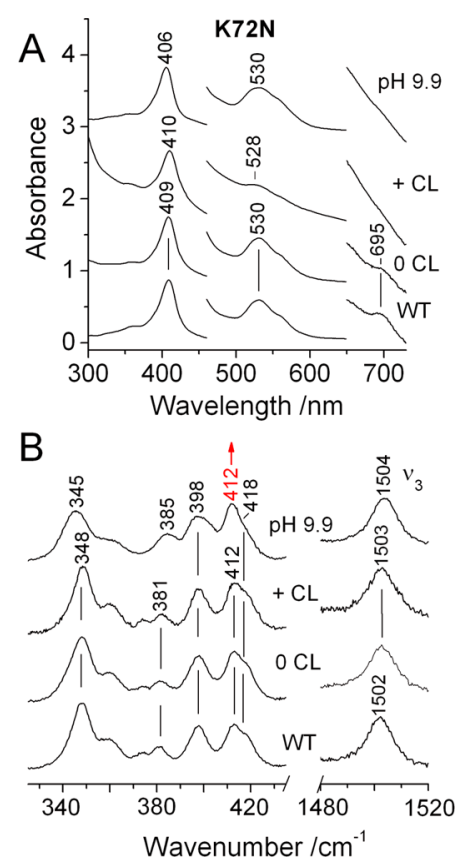

Figure 5. Electronic absorption (A) and resonance Raman (B) spectra of $30 \mu \mathrm{M}$ Lys72Asn mutant in $20 \mathrm{mM}$ Hepes and $0.1 \mathrm{mM}$ EDTA ( $\mathrm{pH}$ 7.0) in the absence and presence of CL vesicles. The CL concentration corresponds to a CL:protein molar ratio of 5 . The spectra of the mutant protein at $\mathrm{pH} 9.9$ in $50 \mathrm{mM}$ glycine and wt at neutral $\mathrm{pH}$ are also shown for comparison. The $460-650$ and $650-730 \mathrm{~nm}$ regions of the absorption spectra are expanded 8 - and 100 -fold, respectively. The ordinate scale refers to the protein at $\mathrm{pH} 7.0$ in the absence of CL. The experimental conditions for the resonance Raman spectra were as follows: laser power at the sample, $6 \mathrm{~mW}$ (Lys72Asn mutant) and 10 $\mathrm{mW}$ (wt); integration time, from 15 to $40 \mathrm{~min}$ (Lys72Asn mutant) and $5 \mathrm{~min}(\mathrm{wt})$. The intensities are normalized to that of the $\nu_{4}$ band (not shown). The arrows and frequencies colored red indicate variations in band intensities that follow the change in protein $\mathrm{pH}$.

and Lys72/73Asn mutants in the absence and presence of CL liposomes. The spectra of the variants at alkaline $\mathrm{pH}$ are also shown. In agreement with the $\mathrm{CD}$ data (Figure 3), comparison of the single-mutant spectra in the absence of $\mathrm{CL}(\mathrm{CL} / \mathrm{cyt} c, 0)$ with those of the wt reveals that a minor population of a misligated alternative LS species with non-native axial iron coordination is induced by the mutations. In particular, comparison with literature data shows that the observed reduced intensity of the CT band at $695 \mathrm{~nm}$, the slight upshift of the high-frequency RR bands (represented by the $\nu_{3}$ mode), and the intensification of the band at $412 \mathrm{~cm}^{-1}$ are consistent with a Lys-Fe-His coordinated misligated species. ${ }^{29,30,37,38}$ Similar but slightly less pronounced effects are observed in the corresponding spectra of the Lys72/73Asn double mutant, indicating that the population of the misligated species is smaller in this mutant. The assignment of the spectral variations induced by mutation to the presence of a small $\mathrm{Lys}-\mathrm{Fe}-\mathrm{His}$ population is consistent with the $\mathrm{RR}$ spectral variations observed in the absence of $\mathrm{CL}$ at alkaline $\mathrm{pH}$, where a Lys$\mathrm{Fe}-$ His population is also expected, ${ }^{36}$ characterized by (i) the loss of the CT band at $695 \mathrm{~nm}$, (ii) an upshift of the core size marker bands, (iii) a downshift of $\nu_{8}$ at $348 \mathrm{~cm}^{-1}$, and (iv) an increase in the intensity of the $412 \mathrm{~cm}^{-1}$ band.

The main effect on the UV-vis spectra of the mutants with an increase in the CL:protein molar ratio is a rapid decrease in the intensity of the $695 \mathrm{~nm}$ band and a clear increase in 


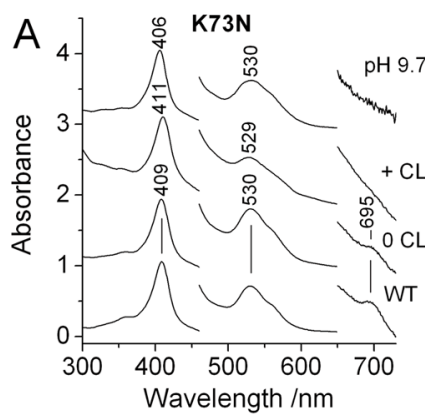

B

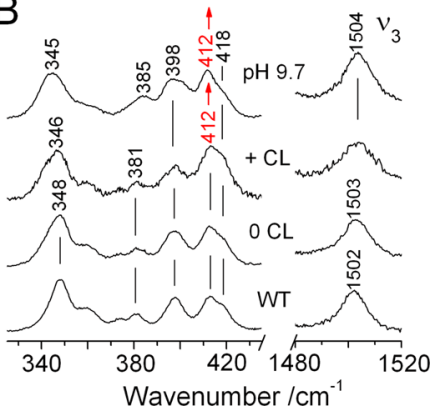

Figure 6. Electronic absorption (A) and resonance Raman spectra (B) of $30 \mu \mathrm{M}$ Lys73Asn mutant in $20 \mathrm{mM}$ Hepes and $0.1 \mathrm{mM}$ EDTA ( $\mathrm{pH}$ 7.0) in the absence and presence of CL vesicles. The CL concentration corresponds to a CL:protein molar ratio of 5 . The spectra of the mutant protein at $\mathrm{pH} 9.7$ in $50 \mathrm{mM}$ glycine and wt at neutral $\mathrm{pH}$ are also shown for comparison. The $460-650$ and $650-730 \mathrm{~nm}$ regions of the absorption spectra are expanded 8 - and 100 -fold, respectively. The ordinate scale refers to the protein at $\mathrm{pH} 7.0$ in the absence of CL. The experimental conditions for the resonance Raman spectra of the mutant were as follows: laser power at the sample, $6 \mathrm{~mW}$; integration time, from 10 to $30 \mathrm{~min}$. For wt, see Figure 5. The intensities are normalized to that of the $\nu_{4}$ band (not shown). The arrows and frequencies colored red indicate the variations in band intensities that follow interaction of the protein with $\mathrm{CL}$ or a change in protein $\mathrm{pH}$.

scattering due to the liposomes, which is the probable origin of the red shift of the Soret band and possibly also the apparent complete disappearance of the CT band for low CL:cyt $c$ molar ratios $(\sim 1.5)$. The $R R$ spectra reveal that the three mutants interact to different degrees with CL. The RR spectra of the Lys72Asn mutant, in the high-frequency (HF) and lowfrequency (LF) regions (Figure 5), are essentially invariant with an increase in CL concentration, indicating that CL does not interact significantly with this variant, as also revealed by the $\mathrm{CD}$ measurements. Conversely, in accord with the $\mathrm{CD}$ data, significant changes are observed in the corresponding spectra of the Lys73Asn and Lys72/73Asn mutants (Figures 6 and 7). The CL-induced changes in the case of the Lys73Asn mutant, although similar to those noted for the wt protein in the presence of $\mathrm{CL}$ where a misligated $\mathrm{Lys}-\mathrm{Fe}-\mathrm{His}$ low-spin species is formed upon CL complexation, ${ }^{28}$ are more pronounced, indicating a more extensive conversion to the misligated Lys-Fe-His species. The RR spectra show progressive variations, particularly an increase in the relative intensity of the band at $412 \mathrm{~cm}^{-1}$ and a frequency downshift of the $\nu_{8}$ mode at $348 \mathrm{~cm}^{-1}$, upon increasing the CL concentration until a CL:cyt $c$ molar ratio of 5 is reached. The enhanced effects of CL complexation observed for the Lys73Asn mutant compared to those for the wt protein are in agreement with the reported higher CL affinity displayed by other Lys73 mutants. ${ }^{7}$ The CL-induced changes observed in the RR spectra of the Lys72/73Asn mutant have some
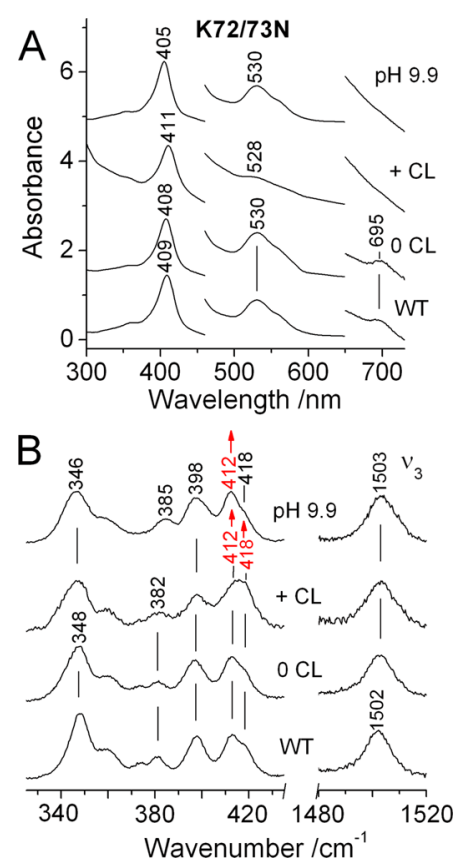

Figure 7. Electronic absorption (A) and resonance Raman (B) spectra of $30 \mu \mathrm{M}$ Lys $72 / 73 \mathrm{Asn}$ mutant in $20 \mathrm{mM}$ Hepes and $0.1 \mathrm{mM}$ EDTA $(\mathrm{pH} 7.0)$ in the absence and presence of $\mathrm{CL}$ vesicles. The CL concentration corresponds to a CL:protein molar ratio of 5. The spectra of the mutant protein at $\mathrm{pH} 9.9$ in $50 \mathrm{mM}$ glycine and wt at neutral $\mathrm{pH}$ are also shown for comparison. The 460-650 and 650$730 \mathrm{~nm}$ regions of the absorption spectra are expanded 8- and 100fold, respectively. The ordinate scale refers to the protein at $\mathrm{pH} 7.0$ in the absence of CL. The experimental conditions for the resonance Raman spectra of the mutant were as follows: laser power at the sample, from 6 to $10 \mathrm{~mW}$; integration time, from 10 to $60 \mathrm{~min}$. For wt, see Figure 5. The intensities are normalized to that of the $\nu_{4}$ band (not shown). The arrows and frequencies colored red indicate the variations in band intensities that follow interaction of the protein with $\mathrm{CL}$ or a change in protein $\mathrm{pH}$.

similarities with those of Lys73Asn, in particular a slight upshift of the core size marker bands and a downshift of the $\nu_{8}$ mode, but an important difference is clearly evident. The lowfrequency RR spectrum of the Lys72/73Asn mutant complex with CL shows an overall intensification of the band centered at $\sim 415 \mathrm{~cm}^{-1}$ indicating an intensification of both the 412 and $418 \mathrm{~cm}^{-1}$ bands (Figure 7 and Figure S1 of the Supporting Information). As reported previously, the relative intensity of these bands can provide a clear means of distinguishing between hexacoordinate low-spin heme species in which the sixth ligand is a Lys or His residue. ${ }^{29,30,37,38}$ The band at 412 $\mathrm{cm}^{-1}$ is typical of a Lys-bound form, as is highlighted by the mutant spectrum at $\mathrm{pH} 9.9$ (Figure 7). Conversely, the intensification of the band at $418 \mathrm{~cm}^{-1}$ is consistent with the changes observed when cyt $c$ adopts a bis-His coordination. ${ }^{38}$ Thus, the RR spectra of the Lys72/73Asn mutant strongly indicate that the misligated species formed upon interaction with $\mathrm{CL}$ is a mixture of Lys-bound (as the wt) and bis-His forms.

To confirm the presence of a bis-His species in the CL complex of the Lys72/73Asn mutant and identify which His residue displaces the native Met80 ligand, the two triple mutants (Lys72/73Asn/His26Tyr and Lys72/73Asn/His33Tyr) were prepared incorporating mutations of His 26 and His33, the two His residues that may substitute for Met80. The 
UV-vis and RR spectra of both Lys72/73Asn/His33Tyr and Lys72/73Asn/His26Tyr mutants in the absence of CL are similar to those of the wt species, indicating that the mutation has little effect on the local heme structure (Figures 8 and 9,
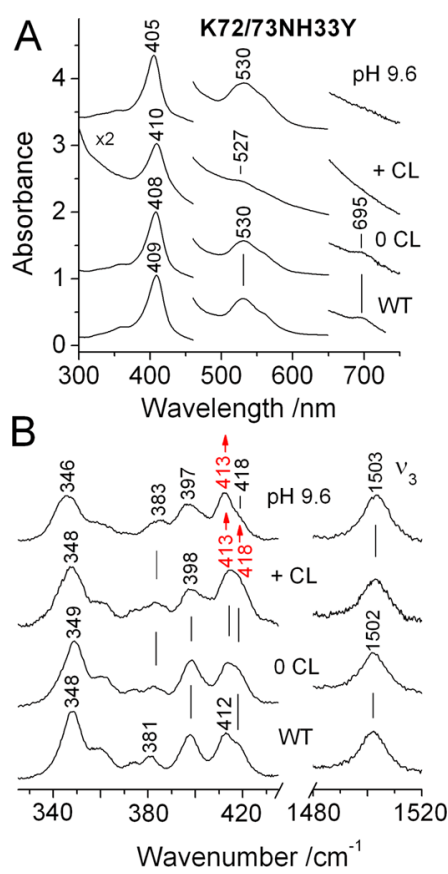

Figure 8. Electronic absorption (A) and resonance Raman (B) spectra of $30 \mu \mathrm{M}$ Lys72/73Asn/His33Tyr mutant in $20 \mathrm{mM}$ Hepes and 0.1 mM EDTA ( $\mathrm{pH} 7.0)$ in the absence and presence of CL vesicles. The $\mathrm{CL}$ concentration corresponds to a CL:protein molar ratio of 7 . The spectra of the mutant protein at $\mathrm{pH} 9.6$ in $50 \mathrm{mM}$ glycine and wt at neutral $\mathrm{pH}$ are also shown for comparison. The 460-650 and 650$730 \mathrm{~nm}$ regions of the absorption spectra are expanded 8- and 100fold, respectively. The ordinate scale refers to the protein at $\mathrm{pH} 7.0$ in the absence of CL. The experimental conditions for the resonance Raman spectra were as follows: laser power at the sample, $3 \mathrm{~mW}$; integration time, from 20 to $40 \mathrm{~min}$. For wt, see Figure 5. The intensities are normalized to that of the $\nu_{4}$ band (not shown). The arrows and frequencies colored red indicate the variations in band intensities that follow interaction of the protein with CL or a change in protein $\mathrm{pH}$.

respectively). Although with an increase in CL concentration the Lys72/73Asn/His33Tyr variant displays spectral variations very similar to those observed for the Lys72/73Asn mutant, in the case of the Lys72/73AsnHis26Tyr variant, a progressive increase in the RR spectra of the relative intensity of the band at $418 \mathrm{~cm}^{-1}$, with the concomitant appearance of a new band at $405 \mathrm{~cm}^{-1}$ (Figure $\mathrm{S} 1$ of the Supporting Information) assigned to the bis-His asymmetric stretching mode $\left[\nu_{\text {as }}\left(\mathrm{Fe}-\mathrm{Im}_{2}\right)\right.$, as previously observed in the spectrum of the $\mathrm{N}$-fragment of cyt $c$ and cyt $c^{\prime \prime 38}$ ], is consistent with the presence of a pure bis-His species, corresponding to His $33-\mathrm{Fe}-\mathrm{His} 18$ coordination.

Furthermore, the variations observed at alkaline $\mathrm{pH}$ for the Lys72/73Asn/His26Tyr variant are consistent with the formation of a misligated species; however, the band typical of Lys-Fe-His coordination at $412 \mathrm{~cm}^{-1}$ does not intensify. A similar result was reported for the single horse heart His26Tyr mutant at alkaline $\mathrm{pH}^{29}$ the low-frequency $\mathrm{RR}$ spectra at alkaline $\mathrm{pH}$ of the two mutants (Lys72/73Asn/His26Tyr and His26Tyr) being very similar.
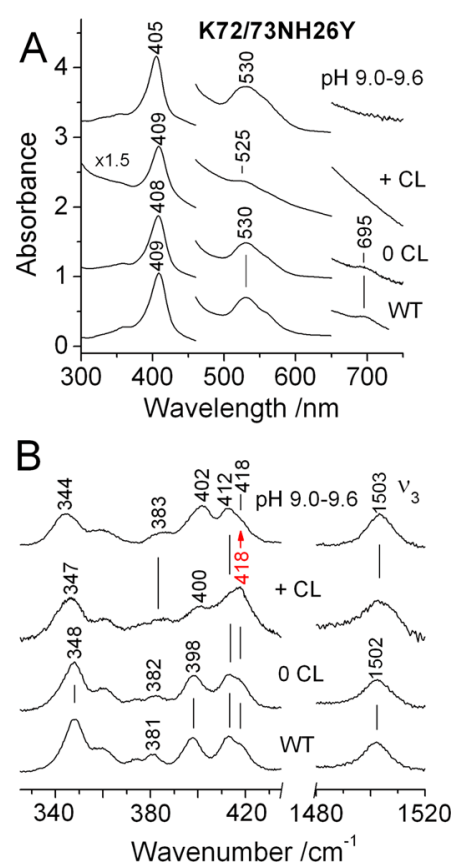

Figure 9. Electronic absorption (A) and resonance Raman (B) spectra of $30 \mu \mathrm{M}$ Lys72/73Asn/His26Tyr mutant in $20 \mathrm{mM}$ Hepes and 0.1 mM EDTA ( $\mathrm{pH} 7.0)$ in the absence and presence of CL vesicles. The $\mathrm{CL}$ concentration corresponds to a CL:protein molar ratio of 7 . The spectra of the mutant protein in the $\mathrm{pH}$ interval of $9.0-9.6$ in $50 \mathrm{mM}$ glycine are invariant and are shown together with the spectrum of wt at neutral $\mathrm{pH}$ for comparison. The $460-650$ and $650-730 \mathrm{~nm}$ regions of the absorption spectra are expanded 8- and 100-fold, respectively. The ordinate scale refers to the protein at $\mathrm{pH} 7.0$ in the absence of CL. The experimental conditions for the resonance Raman spectra were as follows: laser power at the sample, from 3 to $5 \mathrm{~mW}$; integration time, from 20 to $40 \mathrm{~min}$. For wt, see Figure 5. The intensities are normalized to that of the $\nu_{4}$ band (not shown). The arrows and frequencies colored red indicate the variations in band intensities that follow interaction of the protein with CL.

Peroxidase Activity of Mutants. To evaluate the effects of mutation(s) on the cyt c-CL interaction, the steady-state kinetics of the free or CL-bound mutants were investigated and their peroxidase activity was determined. In the absence of CL, all the mutants exhibit $K_{\mathrm{m}}$ and $k_{\text {cat }}$ values for guaiacol closely similar to those observed for the wt protein. Conversely, in contrast with wt cyt $c$, $^{39}$ the addition of CL does not bring about any enhancement of the $k_{\text {cat }} / K_{\mathrm{m}}$ ratio either for the Lys72Asn and Lys79Asn mutants (which do not bind CL) or for the Lys73Asn and Lys72/73Asn mutants (which bind CL) (Table S1 of the Supporting Information).

\section{DISCUSSION}

Effect of Mutation of Lys72, Lys73, and Lys79 on the Global Stability of Horse Heart cyt $c$. These data reveal that the mutations significantly affect the protein structure; the spectroscopic (and, thus, structural) features of the Lys72Asn, Lys73Asn, Lys79Asn, Lys72/73Asn, and Lys72/73/79Asn mutants consistently differ from those of the wt protein. This suggests that when one lysine (or more) is missing, the rearrangement of the region of residues 66-92 alters the heme crevice and the region surrounding Trp59 (Figure 3), thus decreasing protein stability. The biphasic nature of the Gdm$\mathrm{HCl}$-induced mutant denaturation indicates that approximately $42 \%$ of the helical content is lost at the end of the first 
transition (Figure 2). Of the 104 residues constituting the polypeptide chain, 41 residues form the two major ( $\mathrm{N}$ - and $\mathrm{C}$ terminal) and the three minor helix segments of equine cyt $c$. The C-terminal helix (residues 88-102) and the short helix of residues $72-74$ are the segments closest to the mutated region, constituted by a total of 18 residues that correspond to approximately $44 \%$ of the total residues present in the helices of cyt $c$. Although this value is very close to the loss of helix content (42\%) detected by CD, the "foldons theory" elaborated by Englander and collaborators rules out such a possibility. These authors found that the region constituted by the Cterminal and $\mathrm{N}$-terminal helices is the first region to fold and the last to unfold in the folding-unfolding process of cyt $c$. $^{35}$ Therefore, the helices of residues 50-54 and 61-68 are the segments expected to unfold during the first transition. Because the helix of residues $72-74$ is also missing in the mutants, the number of residues released when these helices unfold would be 16 , corresponding to $\sim 40 \%$ of the total number of helixforming residues (41 side chains). Thus, the invariant Lys 72 and Lys79 and the largely invariant Lys73 contribute to the stabilization of the helix regions and of the Met80-Fe(III) axial bond; the $\mathrm{RR}$ and $\mathrm{CD}$ spectra of the mutants reveal that approximately $30 \%$ of the protein population possesses nonnative heme coordination. This subpopulation was not observed in previous reports where the lysines were mutated to alanines; ${ }^{10,40}$ in this regard, it must be taken into account that, at variance with Ala, Asn is capable of forming multiple hydrogen bonds both with water molecules and with other protein polar groups. Thus, although the precise role of Asn residues in the formation of this subpopulation remains obscure at this stage, it is possibly linked to the ability of Asn residues to stabilize an alternative backbone conformation through formation of hydrogen bonds.

Equally intriguing is the observation that single and multiple mutations induce the same effect on protein stability. This suggests that the effect produced by single mutations is not necessarily locally restricted; it can act as a "long-range" effect that induces unfolding of the 60s helix segment, an increased flexibility of the region of residues 66-92, and the rupture of the native Met80-Fe(III) axial bond, thus favoring formation of the observed non-native coordinated subpopulation.

Role of Lys72, Lys73, and Lys79 in the cyt c-CL Binding Reaction. The models proposed to date to describe the cyt $c-C L$ complex have identified several regions of the protein that may act as host sites for the insertion of the acyl chain(s) of the polyphosphate. In particular, the "extended cardiolipin anchorage to cyt $c$ " theory identified the hydrophobic region located close to the Asn52-containing short helix as a probable host site, ${ }^{19}$ and recently, our study of the Asn52Ile mutant-CL interaction has indeed provided evidence that the region close to the Asn52 residue is deeply involved in the binding process. ${ }^{8}$ The model of Kalanxhi and Wallace identifies, instead, the region of residues 66-92, which comprises the cleft formed by residues $67-71$ and $82-85$ and where the network of positively charged residues (i.e., Lys72, Lys73, and Lys86) may facilitate the access of the acyl chain. ${ }^{7}$ Therefore, in this paper, we extend the study to the region of residues 66-92 that Kalanxhi and Wallace consider "crucial" for the cyt c-CL binding process. ${ }^{7}$ The studies performed to date envisage Lys 72 and Lys73 as the residues directly involved in molecular recognition, while Lys79 is considered to be the best candidate to substitute for Met80 as the heme-iron axial ligand upon formation of the cyt $c-C L$ complex. ${ }^{5-8}$ Our data show that the replacement of either Lys72 or Lys79 hinders formation of the cyt $c-C L$ complex. The evidence that these residues are directed toward the solvent in the wt protein (Figure 1, left panel) suggests that they are important in protein-CL recognition. We propose that the cyt $c-C L$ binding process occurs in two steps; in the first step, the positively charged Lys72 and Lys79 interact electrostatically with the deprotonated phosphate groups located on the liposome surface, and in the second step, the acyl chain of CL enters the protein. Thus, Lys 72 and Lys79 facilitate the correct orientation for insertion of the acyl chain into the protein. Furthermore, as Lys79 is the amino acid assumed to replace Met80 as the axial ligand of the heme iron at alkaline $\mathrm{pH}$, we envisage that a similar event may take place during formation of the cyt $c-C L$ complex at neutral $\mathrm{pH}^{8,31,41,42}$ The unfolding of the region of residues $60-92$ induced by the insertion of the acyl chain destabilizes the native Met80-Fe(III) axial bond and facilitates the replacement of the Met80 residue as the axial ligand by another residue, identified by RR measurements as Lys79. These results in part rectify the extended cardiolipin anchorage to cyt $c$ model, which proposed Lys 72 and Lys73 as the residues involved in the molecular recognition with $\mathrm{CL}^{7}$ on the other hand, they are in agreement with our model asserting that the CL phosphate groups interact with the protein in the vicinity of the Lys 72 and Lys79 amino groups. ${ }^{8}$

In contrast with previous reports, ${ }^{5,7}$ our data rule out a crucial role of Lys73 for cyt c-CL liposome recognition; in the absence of this residue, formation of the complex proceeds in a manner similar to that of the wt protein. Unlike Lys 72 and Lys79, Lys73 is engaged in two salt bridges with the acidic Glu66 and Glu69 residues (Figure 1, right panel). Therefore, the Lys73Asn mutant reacts with $\mathrm{CL}$ because the molecular recognition promoted by Lys72 and Lys79 permits the insertion of the acyl chain into the protein. However, the process requires more time because, in the absence of Lys73, the two salt bridges with Glu66 and Glu69 are lost and the structural rearrangement of the segment of residues $75-87$ (i.e., the region where residues Lys 72 and Lys79 are located) likely hinders the insertion of the acyl chain of CL.

The binding reaction of the Lys72/73Asn mutant gave unexpected results, because the simultaneous mutation of Lys 72 and Lys73 does not abolish the binding of CL to the protein. No unequivocal explanation can be provided on the basis of the results presented here; it may be tentatively imputed to the loss of the salt bridges that Lys 73 forms with Glu66 and Glu69. The more flexible, less folded rearrangement of the region of residues 66-92 may facilitate the insertion of the acyl chain of CL even in the absence of one of the residues considered to be important for molecular recognition. However, this point needs further investigation to be unequivocally clarified.

As for the other mutants, the $\mathrm{K} 72 / 73 \mathrm{~N}$ mutant possesses a minor Lys-Fe-His coordinated misligated species at neutral $\mathrm{pH}$; however, when bound to $\mathrm{CL}$, it shows also the formation of a bis-His species. Three histidines are present in horse cyt $c:{ }^{43}$ (i) the proximal heme-iron ligand His 18, (ii) His26 that, H-bonded to the backbone carbonyl of Pro44, maintains the 20 s and 40 s $\Omega$-loops joined and sterically close [thereby enhancing the overall rigidity of the macromolecule, the stability of the heme crevice, and the strength of the native Met80-Fe(III)-His coordination], ${ }^{30,44}$ and (iii) His33, which is located in the 20s $\Omega$-loop. The similarity between the RR spectra of the Lys72/73Asn and Lys72/73Asn/His33Tyr 
mutants in the presence of CL (Figures 7 and 8 and Figure S1 of the Supporting Information) suggests that His 26 is coordinated to the heme iron in the Lys72/73Asn mutant. The bis-His coordination is intriguing, but difficult to rationalize on a structural basis. However, the following mechanism can be hypothesized: in wt cyt $c$, the 20 s and $40 \mathrm{~s}$ $\Omega$-loops are bridged with His26 through H-bonds that this residue forms with Asn 31 and the backbone carbonyl of Pro44; the constraints imposed on the His 26 residue by its H-bonds with the asparagine side chain and the backbone carbonyl of Pro44 impair the structural flexibility of the two $\Omega$-loops. This characteristic provides a significant contribution to protein rigidity. The binding of $C L$ is associated with a partial unfolding of cyt $c$ that generates a greater mobility of protein segments. The bis-His coordination of the CL-bound protein observed in the absence of both Lys72 and Lys73 indicates that a global protein rearrangement occurs, His 26 and His 33 being located on the opposite side of the macromolecule with respect to Lys72, Lys73, and Lys79. When CL binds, in the absence of both Lys72 and Lys73, it is possible that the H-bonds that His 26 forms in the free protein are lost and the free 20s and 40s $\Omega$-loops may induce a peculiar, more dynamic structural rearrangement favoring the insertion of the acyl chain of $\mathrm{CL}$ and the repositioning of His26 in the vicinity of the heme with subsequent coordination to the iron. The bis-His coordination of the CL-bound Lys72/73Asn mutant suggests that this conformer is less folded than the other CL-bound mutants; it is structurally similar to the molten globule state of cyt $c$, which also possesses a bis-His coordination. ${ }^{45}$ Note that the far-UV $\mathrm{CD}$ measurements exclude any possibility of protein denaturation (Figure S4 of the Supporting Information). The formation of a bis-His species in the double and Lys72/73Asn/His33Tyr mutants provides further evidence that Lys72 and Lys73 are crucial for protein stability. Accordingly, in the CL-Lys72/ 73Asn/His26Tyr complex, in the absence of Lys72 and Lys73 and the H-bond that links the 20s and 40s $\Omega$-loops and brings them sterically close, a major structural rearrangement that allows His 33 to coordinate to the heme iron occurs.

The tertiary conformational changes occurring in the mutants, including those in the heme crevice region where Met80 is displaced from the axial coordination position, can offer a possible explanation for the lack of peroxidase activity of the CL-bound mutants (see Table S1 of the Supporting Information). A five-coordinate form is necessary for peroxidase activity; hence, the observation that the CL-bound mutants are pure six-coordinate proteins, with a lysine (and also a histidine in the case of the Lys72/73Asn double mutant) axially bound to the heme iron, is consistent with the absence of peroxidase activity. Conversely, the wt protein is characterized by a mixture of six-coordinate and five-coordinate populations for high concentrations of $\mathrm{CL}$, in agreement with the peroxidase activity displayed by the cyt $c-\mathrm{CL}$ complex. ${ }^{8}$ However, further work is necessary to confirm this important observation.

On the whole, our data show that (i) Lys72 and Lys79 are crucial for cyt $c-C L$ recognition and, thus, for complex formation and (ii) Lys73 also plays a role in the cyt $c-C L$ interaction. Although not directly involved in the molecular recognition mechanism, this residue contributes to the overall rigidity of the region of residues 66-92 through the salt bridges it forms with Glu66 and Glu69, thus facilitating the insertion of the acyl chain of CL. Hence, as Lys72 and Lys79, this residue also plays a critical role in the first steps of the apoptotic process.

In conclusion, our results show that the Lys72, Lys73, and Lys79 residues not only are important for protein stabilization but also permit the protein to initiate the apoptotic process catalyzing $\mathrm{CL}$ peroxidation.

\section{ASSOCIATED CONTENT}

\section{Supporting Information}

Curve fitting of the low-frequency RR spectra, electronic absorption and RR spectra of Lys79Asn and Lys72/73/79Asn mutants in the absence and presence of CL vesicles, far-UV CD spectrum of the Lys72/73Asn mutant in the absence and presence of CL vesicles, and a table listing the parameters regarding the peroxidase activity of mutants in the absence and presence of CL. This material is available free of charge via the Internet at http://pubs.acs.org.

\section{AUTHOR INFORMATION}

\section{Corresponding Author}

*Via Montpellier 1, 00133 Roma, Italy. E-mail: santucci@med. uniroma2.it. Telephone: (+39) 0672596364.

\section{Funding}

This work was supported by MIUR PRIN 2010C4R8M8 (G.S.).

\section{Notes}

The authors declare no competing financial interest.

\section{ABBREVIATIONS}

cyt $c$, cytochrome $c$; wt, wild type; CL, cardiolipin; $\mathrm{CD}$, circular dichroism; RR, resonance Raman.

\section{REFERENCES}

(1) Garrido, C., Galluzzi, L., Brunet, M., Puig, P. E., Didelot, C., and Kroemer, G. (2006) Mechanisms of cytochrome $c$ release from mitochondria. Cell Death Differ. 13, 1423-1433.

(2) Santucci, R., Sinibaldi, F., Patriarca, A., Santucci, D., and Fiorucci, L. (2010) Misfolded proteins and neurodegeneration: Role of nonnative cytochrome $c$ in cell death. Expert Rev. Proteomics 7, 507-517.

(3) Green, D. R., and Reed, J. C. (1998) Mitochondria and apoptosis. Science 281, 1309-1312.

(4) Kagan, V. E., Tyurin, V. A., Jiang, J., Tyurina, Y. Y., Ritov, V. B., Amoscato, A. A., Osipov, A. N., Belikova, N. A., Kapralov, A. A., Kini, V., Vlasova, I. I., Zhao, Q., Zou, M., Di, P., Svistunenko, D. A., Kurnikov, I. V., and Borisenko, G. G. (2005) Cytochrome $c$ acts as a cardiolipin oxygenase required for release of proapoptotic factors. Nat. Chem. Biol. 1, 223-232.

(5) Rytömaa, M., and Kinnunen, P. K. (1995) Reversibility of the binding of cytochrome $c$ to liposomes. Implications for lipid-protein interactions. J. Biol. Chem. 270, 3197-31202.

(6) Sinibaldi, F., Fiorucci, L., Patriarca, A., Lauceri, R., Ferri, T., Coletta, M., and Santucci, R. (2008) Insights into cytochrome ccardiolipin interaction. Role played by ionic strength. Biochemistry 47, 6928-6935.

(7) Kalanxhi, E., and Wallace, C. J. A. (2007) Cytochrome $c$ impaled: Investigation of the extended lipid anchorage of a soluble protein to mitochondrial membrane models. Biochem. J. 407, 179-187.

(8) Sinibaldi, F., Howes, B. D., Piro, M. C., Polticelli, F., Bombelli, C., Ferri, T., Coletta, M., Smulevich, G., and Santucci, R. (2010) Extended cardiolipin anchorage to cytochrome $c$ : A model for proteinmitochondrial membrane binding. J. Biol. Inorg. Chem. 15, 689-700.

(9) Schug, Z. T., and Gottlieb, E. (2009) Cardiolipin acts as a mitochondrial signaling platform to launch apoptosis. Biochim. Biophys. Acta 1788, 2022-2031. 
(10) Rajagopal, B. S., Silkstone, G. G., Nicholls, P., Wilson, M. T., and Worrall, J. A. (2012) An investigation into a cardiolipin acyl chain insertion site in cytochrome c. Biochim. Biophys. Acta 1817, 780-791.

(11) Caroppi, P., Sinibaldi, F., Fiorucci, L., and Santucci, R. (2009) Apoptosis and human diseases: Mitochondrion damage and lethal role of cytochrome $c$ as proapoptotic protein. Curr. Med. Chem. 16, 40584065 .

(12) Ott, M., Zhivotovsky, B., and Orrenius, S. (2007) Role of cardiolipin in cytochrome $\mathrm{c}$ release from mitochondria. Cell Death Differ. 14, 1243-1247.

(13) Hanske, J., Toffey, J. R., Morenz, A. M., Bonilla, A. J., Schiavoni, K. H., and Pletneva, E. V. (2012) Conformational properties of cardiolipin-bound cytochrome c. Proc. Natl. Acad. Sci. U.S.A. 109, 125130.

(14) Nantes, I. L., Kawai, C., Pessoto, F. S., and Mugnol, K. C. (2010) Study of respiratory cytochromes in liposomes. Methods Mol. Biol. 606, 147-165.

(15) Godoy, L. C., Muñoz-Pinedo, C., Castro, L., Cardaci, S., Schonhoff, C. M., King, M., Tórtora, V., Marín, M., Miao, Q., Jiang, J. F., Kapralov, A., Jemmerson, R., Silkstone, G. G., Patel, J. N., Evans, J. E., Wilson, M. T., Green, D. R., Kagan, V. E., Radi, R., and Mannick, J. B. (2009) Disruption of the M80-Fe ligation stimulates the translocation of cytochrome $c$ to the cytoplasm and nucleus in nonapoptotic cells. Proc. Natl. Acad. Sci. U.S.A. 106, 2653-2658.

(16) Vladimirov, Y. A., Proskurnina, E. V., Izmailov, D. Y., Novikov, A. A., Brusnichkin, A. V., Osipov, A. N., and Kagan, V. E. (2006) Cardiolipin activates cytochrome $c$ peroxidase activity since it facilitates $\mathrm{H}_{2} \mathrm{O}_{2}$ access to heme. Biochemistry (Moscow) 71, 998-1005.

(17) Belikova, N. A., Vladimirov, Y. A., Osipov, A. N., Kapralov, A. A., Tyurin, V. A., Potapovich, M. V., Basova, L. V., Peterson, J., Kurnikov, I. V., and Kagan, V. E. (2006) Peroxidase activity and structural transitions of cytochrome $c$ bound to cardiolipin-containing membranes. Biochemistry 45, 4998-5009.

(18) Hüttemann, M., Pecina, P., Rainbolt, M., Sanderson, T. H., Kagan, V. E., Samavati, L., Doan, J. W., and Lee, I. (2011) The multiple functions of cytochrome $c$ and their regulation in life and death decisions of the mammalian cell: From respiration to apoptosis. Mitochondrion 11, 369-381.

(19) Rytömaa, M., and Kinnunen, P. K. J. (1994) Evidence for two distinct acidic phospholipids-binding sites in cytochrome c. J. Biol. Chem. 269, 1770-1774.

(20) Tuominem, E. K., Wallace, C. J., Clark-Lewis, I., Craig, D. B., Rytömaa, M., and Kinnunen, P. K. (2002) Phospholipid-cytochrome $c$ interaction: Evidence for the extended lipid anchorage. J. Biol. Chem. 277, 8822-8826.

(21) Stewart, J. M., Blakely, J. A., and Johnson, M. D. (2000) The interaction of ferrocytochrome $\mathrm{c}$ with long-chain fatty acids and their CoA and carnitine esters. Biochem. Cell Biol. 78, 675-681.

(22) Schlame, M., and Ren, M. (2009) The role of cardiolipin in the structural organization of mitochondrial membranes. Biochim. Biophys. Acta 1788, 2080-2083.

(23) Schug, Z. T., and Gottlieb, E. (2009) Cardiolipin acts as a mitochondrial signalling platform to launch apoptosis. Biochim. Biophys. Acta 1788, 2022-2031.

(24) Patel, C. N., Lind, M. C., and Pielak, G. J. (2001) Characterization of horse cytochrome c expressed in Escherichia coli. Protein Expression Purif. 22, 220-224.

(25) Bergstrom, C. L., Beales, P. A., Lv, Y., Vanderlick, T. K., and Groves, J. T. (2013) Cytcochrome c causes pore formation in cardiolipin-containing membranes. Proc. Natl. Acad. Sci. U.S.A. 110, 6269-6274.

(26) Kluck, R. M., Ellerby, L. M., Ellerby, H. M., Naiem, S., Yaffe, M. P., Margoliash, E., Bredesen, D., Mauk, A. G., Sherman, F., and Newmeyer, D. D. (2000) Determinants of cytochrome c pro-apoptotic activity. The role of lysine 72 trimethylation. J. Biol. Chem. 275, 16127-16133.

(27) Sinibaldi, F., Mei, G., Polticelli, M., Piro, M. C., Howes, B. D., Smulevich, G., Santucci, R., Ascoli, F., and Fiorucci, L. (2005) ATP specifically drives refolding of nonnative conformations of cytochrome c. Protein Sci. 14, 1049-1058.

(28) Sinibaldi, F., Droghetti, E., Ponticelli, F., Piro, M. C., Di Pierro, D., Ferri, T., Smulevich, G., and Santucci, R. (2011) The effects of ATP and sodium chloride on the cytochrome c-cardiolipin interaction: The contrasting behaviour of the horse heart and yeast proteins. J. Inorg. Biochem. 105, 1365-1372.

(29) Sinibaldi, F., Howes, B. D., Piro, M. C., Caroppi, P., Mei, G., Ascoli, F., Smulevich, G., and Santucci, R. (2006) Insights into the role of the histidines in the structure and stability of cytochrome c. J. Biol. Inorg. Chem. 11, 52-62.

(30) Sinibaldi, F., Piro, M. C., Howes, B. D., Smulevich, G., Ascoli, F., and Santucci, R. (2003) Rupture of the H-bond linking two $\Omega$-loops induces the molten globule state at neutral $\mathrm{pH}$ in cytochrome $c$. Biochemistry 42, 7604-7610.

(31) Pollock, W. B., Rosell, F. I., Twitchett, M. B., Dumont, M. E., and Mauk, A. G. (1998) Bacterial expression of a mitochondrial cytochrome $c$. Trimethylation of Lys 72 in yeast iso-1-cytochrome $c$ and the alkaline conformational transition. Biochemistry 37, 61246131.

(32) Hu, S., Morris, I. K., Singh, J. P., Smith, K. M., and Spiro, T. G. (1993) Complete assignment of cytochrome $c$ resonance Raman spectra via enzymatic reconstitution with isotopically labeled hemes. $J$. Am. Chem. Soc. 115, 12446-12458.

(33) Maity, H., Maity, M., and Englander, S. W. (2004) How cytochrome $c$ folds, and why: Submolecular foldon units and their stepwise sequencial stabilization. J. Mol. Biol. 343, 223-233.

(34) Pielak, G. J., Oikawa, K., Mauk, A. G., Smith, M., and Kay, C. M. (1986) Elimination of the negative Soret Cotton effect of eukariotic cytochromes $c$ by replacement of an invariant phenylalanine residue by site-directed mutagenesis. J. Am. Chem. Soc. 108, 2724-2727.

(35) Santucci, R., and Ascoli, F. (1997) The Soret CD spectrum as a probe for the heme $\mathrm{Fe}(\mathrm{III})-\mathrm{Met}(80)$ axial bond in horse cytochrome $c$. J. Inorg. Biochem. 68, 211-214.

(36) Dopner, S., Hildebrandt, P., Rosell, F. I., and Mauk, A. G. (1998) Proton-linked protein conformational switching: Definition of the alkaline conformational transition of yeast iso-1-ferri-cytochrome $\mathrm{c}$. J. Am. Chem. Soc. 120, 11246-11255.

(37) Caroppi, P., Sinibaldi, F., Santoni, E., Howes, B. D., Fiorucci, L., Ferri, T., Ascoli, F., Smulevich, G., and Santucci, R. (2004) The 40's $\Omega$-loop plays a critical role in the stability and the alkaline conformational transition of cytochrome c. J. Biol. Inorg. Chem. 9, 997-1006.

(38) Santoni, E., Scatragli, S., Sinibaldi, F., Fiorucci, L., Santucci, R., and Smulevich, G. (2004) A model for the misfolded bis-His intermediate of cyt $c$ : The 1-56 N-fragment. J. Inorg. Biochem. 98, 1067-1077.

(39) Schlame, M., Rua, D., and Greenberg, M. L. (2000) The biosynthesis and functional role of cardiolipin. Prog. Lipid Res. 39, 257-288.

(40) Rosell, F. I., Ferrer, J. C., and Mauk, A. G. (1998) Proton-linked protein conformational switching: Definition of the alkaline conformational transition of yeast iso-1-ferricytochrome c. J. Am. Chem. Soc. 120, 11234-11245.

(41) Oellerich, S., Lecomte, S., Paternostre, M., Heimburg, T., and Hildebrandt, P. (2004) Peripherical and integral binding of cytochrome $c$ to phospholipids vesicles. J. Phys. Chem. B 108, 38713878.

(42) Mugnol, K. C. U., Ando, R. A., Nagayasu, R. Y., Faljoni-Alario, A., Brochsztain, S., Santos, P. S., Nascimento, O. R., and Nantes, I. L. (2008) Spectroscopic, structural, and functional characterization of the alternative low-spin state of horse heart cytochrome c. Biophys. J. 94, 4066-4077.

(43) Moore, G. R., and Pettigrew, G. W. (1990) Cytochromes c. Evolutionary, Structural and Physicochemical Aspects, Springer-Verlag, New York.

(44) Balakrisnan, G., Hu, Y., and Spiro, T. G. (2012) His26 protonation in cytochrome $\mathrm{c}$ triggers microsecond $\beta$-sheet formation 
and heme exposure: Implications for apoptosis. J. Am. Chem. Soc. 134, 19061-19069.

(45) Santucci, R., Bongiovanni, C., Mei, G., Ferri, T., Polizio, F., and Desideri, A. (2000) Anion size modulates the structure of the A state of cytochrome c. Biochemistry 39, 12632-12638.

(46) Banci, L., Bertini, I., Gray, H. B., Luchinat, C., Reddig, T., Rosato, A., and Turano, P. (1997) Solution structure of oxidized horse heart cytochrome c. Biochemistry 36, 9867-9877.

(47) Pettersen, E. F., Goddard, T. D., Huang, C. C., Couch, G. S., Greenblatt, D. M., Meng, E. C., and Ferrin, T. E. (2004) UCSF Chimera: A visualization system for exploratory research and analysis. J. Comput. Chem. 25, 1605-1612. 